\title{
ЭКОЛОГИЧЕСКИ ОБОСНОВАННЫЕ
}

\section{ПАРАМЕТРЫ ДИФФЕРЕНЦИРОВАННЫХ} РЕЖИМОВ ОРОШЕНИЯ ОСНОВНЫХ СЕЛЬСКОХОЗЯЙСТВЕННЫХ КУЛЬТУР СТЕПНОЙ И СУХОСТЕПНОЙ ЗОН ПОВОЛЖЬЯ

\author{
ENVIRONMENTALLY JUSTIFIED PARAMETERS OF \\ DIFFERENTIATED IRRIGATION REGIMES OF MAIN \\ AGRICULTURAL CULTURES OF STEPPE ANDDRY-STEPPE \\ ZONE OF THE VOLGA REGION
}

\author{
В.А. Шадских, доктор сельскохозяйственных наук, профессор, \\ заслуженный работник сельского хозяйства РФ, \\ B.E. Кижаева, кандидат сельскохозяйственных наук, \\ Л.г. Романова, кандидат сельскохозяйственных наук, \\ о.Л. Рассказова
}

Волжский научно-исследовательский институт гидротехники и мелиорации
V.A. Shadskikh, doctor of agricultural sciences, professor, honored worker of agriculture of the Russian Federation, V.E. Kizhaeva, candidate of agricultural sciences, L.G. Romanova, candidate of agricultural sciences, O.L. Rasskazova

Volga Scientific-Research Institute of Hydraulic Engineering and Land Reclamation
Современное состояние сельскохозяйственного производства в Поволжье свидетельствует о том, что на фоне климатических изменений, снижения плодородия почв, деградации почвенного покрова и рыночных отношений использование влагосберегающих, почвозащитных мелиораций в данном регионе является актуальным. Статья освещает вопросы развития мелиоративного земледелия и его влияния на повышение продуктивности и экологической безопасности орошаемых земель, сохранение плодородия и экологическое состояние мелиоративных агроландшафтов Поволжского региона за счет эффективного использования водных ресурсов на орошаемом поле. На основании многолетних исследований гидрогеохимического режима орошаемых земель представлена разработанная структура водопользования, обеспечивающая формирование экологически благоприятного мелиоративного режима и сохранение автоморфных условий почвообразования для зоны сухостепного Заволжья. Приведены экологически обоснованные нормы орошения по агроландшафтным зонам Поволжья, полученные в результате исследований по изучению режимов орошения сельхозкультур На основании разработанной методики рассчитаны экологически безопасные оросительные нормы сельхозкультур сухостепного Поволжья. Теоретически обоснованные и практически проверенные поливные нормы составляют 300-350 м³ $/ г$ в начале вегетации сельскохозяйственных культур и не более $450-500 \mathrm{~m}^{3}$ /га в период их максимального водопотребления. На полях с близким уровнем грунтовых вод (2-3 м) поливные нормы должны исключать инфильтрацию и не превышать $250-350 \mathrm{~m}^{3} /$ га.
The current state of agricultural production in the Volga region indicates that against the background of climate change, reduced soil fertility, degradation of soil cover and market relations, the use of moisture-saving, soil-protective melioration in this region is relevant. The article highlights the development of reclamation agriculture and their impact on improving the productivity and environmental safety of irrigated land, the preservation of fertility and the ecological state of reclamation agricultural landscapes of the Volga region through the effective use of water resources in the irrigated field. On the basis of long-term researches of the hydrogeochemical regime of irrigated lands the developed structure of water use providing formation of ecologically favorable meliorative regime and preservation of automorphic conditions of soil formation for the zone of the dry steppe of the Volga region is presented. Environmentally sound irrigation norms for agro-landscape zones of the Volga region, obtained as a result of studies on the irrigation regimes of crops, are presented. Based on the developed methodology the environmentally sound irrigation norms of agricultural crops in the dry steppe of the Volga region. Theoretically justified and practically tested irrigation norms are $300-350 \mathrm{~m}^{3} /$ ha at the beginning of the growing season of crops and no more than 450-500 $\mathrm{m} 3 /$ ha during their maximum water consumption. In fields with close groundwater level (2-3 m) irrigation norms should exclude infiltration and not exceed 250 $350 \mathrm{~m}^{3} /$ ha.
Ключевые слова: мелиорация, режим орошения, оптимизация водного режима, экология, агроландшафт
Key words: land reclamation, irrigation regime, optimization of water regime, ecology, agrolandscape 
Введение. В нашей стране более $80 \%$ сельхозугодий размещено в зоне рискованного земледелия с недостаточным и неустойчивым естественным увлажнением. Из них 35\% посевных площадей (45 млн га) находятся в степных засушливых районах с общим количеством осадков от 250 до 400 мм и систематически подвергаются засухе [5, 6]. Поэтому проблема влагообеспеченности и стабильности производства сельскохозяйственной продукции стоит очень остро.

Земледелие в Поволжье во многом определяется природно-климатическими факторами, оказывающими основное влияние на урожайность сельскохозяйственных культур и качество продукции. Задача земледелия - регулировать такие факторы, как соотношение углекислого газа, кислорода, воды, элементов питания, и их количество для достижения максимальной урожайности культурных растений и высокого качества растениеводческой продукции.

Поволжье является одним из крупнейших экономических районов России. Сельское хозяйство этой территории специализируется на выращивании зерновых культур (которые занимают более $60 \%$ общей площади пашни), в основном яровой пшеницы твердых сортов, озимой пшеницы, проса, технических культур (подсолнечника, сахарной свеклы, горчицы), а также бахчевых и овощных культур. Однако следует отметить, что Приволжский федеральный округ отличается не только большим объемом производства сельскохозяйственной продукции, но и большими ее потерями (до 25\%) [6]. Для исключения отрицательных последствий орошения на природную среду таких, как водная эрозия и ухудшение водно-физических свойств почв, инфильтрационные потери и подъем уровня грунтовых вод, засоление почв и снижение плодородия орошаемых земель, необходимо соблюдение научно обоснованных требований к структуре водопользования и режимам орошения сельскохозяйственных культур $[2,11,13]$.

Целью данной работы являлась разработка экологически обоснованного режима орошения для основных сельскохозяйственных культур степной и сухостепной зон Поволжья с учетом дифференцирования норм и сроков поливов по фазам роста и развития растений.

Материалы и методы. Исследования проводили в период с 2006 по 2018 годы на темно-каштановых почвах в засушливой зоне Поволжья на территории опытно-производственного участка ВолжНИиГиМ.

Расчет режима орошения, то есть норм, числа и сроков поливов, выполняли на основании физиологических закономерностей водопотребления растений и почвенно-климатической характеристики региона. При расчете режима орошения и экологически безопасных поливных и оросительных норм использовали уравнение водного баланса, учитывающее в обобщенном виде агроклиматические особенности территории, биологические особенности возделываемой сельскохозяйственной культуры, свойства почв, гидрогеологические условия орошаемого поля, способы и технику полива $[1,6]$. Расчет режима орошения выполняли посредством имитационного моделирования, позволяющего учитывать все многообразие факторов, определяющих эколого-экономически целесообразные оросительные и поливные нормы сельскохозяйственных культур в конкретных условиях.

Норму полива устанавливали в зависимости от предполивной влажности и глубины увлажнения с учетом водоудерживающей способности почвы, исключая потери на инфильтрацию в грунтовые воды. При определении нормы полива принимали во внимание, что полив следует проводить без стока за пределы поля. Достоковая норма полива зависит от его интенсивности, впитывающей способности почвы и интенсивности дождевания. Пестрота увлажнения по площади поля, переполив или недополив исключаются тогда, когда средняя интенсивность соответствует средней скорости впитывания влаги в почву $[7,9,10$, 16]. При поливе дождеванием - наиболее распространенном в Поволжье - достоковую поливную норму устанавливают в зависимости от энергетических характеристик дождя, уровня предполивной влажности, объемной массы почвы $[3,8]$.

Сроки и нормы полива сельскохозяйственных культур дифференцировали на основе рассчитанной экологически допустимой оросительной нормы [14].

Суммарное водопотребление рассчитывали по коэффициенту водопотребления и планируемой урожайности (по А.Н. Костякову) [4, 8]. Усредненные коэффициенты водопотребления и суммарного водопотребления основных культур засушливой зоны Поволжья были рассчитаны в ходе многолетних исследований, проводимых учеными ВолжНИИГиМ [8, $9,12,13]$.

Поливы распределяли так, чтобы обеспечить влагой растения в «критические периоды», когда они наиболее чувствительны к подсушиванию почвы $[8,11,13$, 15]. При этом нормы поливов рассчитывали с учетом того, чтобы влажность почвы не была ниже оптимального предела.

Начало и продолжительность «критических периодов» зависели от конкретной сельскохозяйственной культуры и соответствовали фазам ее развития. Так, для озимой пшеницы они совпадали с фенологическими периодами: возобновление вегетации, трубкование-колошение, цветение-налив, молочная спелость; для кукурузы: посев-всходы, 5-7 настоящих листьев, выбрасывание метелки, молочная спелость; для люцерны второго-третьего года: возобновление вегетации, стебление-бутонизация, цветение; для суданской травы: всходы-кущение, выметывание метелки-цветение, формирование второго и третьего укосов; для сои на зерно: всходы-ветвление, бутонизация-цветение, налив зерна-созревание.

Результаты и обсуждение. Исходя из водно-физических характеристик почв Поволжья были рассчитаны предельные поливные нормы. Результаты расчетов показали, что запас активной (капиллярной) влаги в черноземах Поволжья примерно в два раза выше, чем в светлокаштановых почвах. Темно-каштановые и каштановые почвы, несмотря на значительную разницу в содержании гумуса, по запасу активной влаги различались незначительно.

Было выявлено, что запас активной влаги в почве определяется мощностью корнеобитаемого слоя и содержанием капиллярных пор, обусловленным гранулометрическим составом и структурой почвы. Запас активной влаги закономерно увеличивается с ростом содержания крупнопылеватых частиц или глинистых микроагрегатов того же размера. При уплотнении почв, приводящем к уменьшению количества капиллярных пор, запас активной влаги снижается.

На основании выполненных расчетов были разработаны дифференцированные режимы орошения основных сельскохозяйственных культур засушливой зоны Поволжья.

Для озимых культур (пшеницы, ржи) наиболее эффективен режим орошения с поддержанием предполивной влажности почвы в периоды всходов и кущения $80 \%$ НВ, в последующие фазы развития $70-75 \%$ НВ, в период налива зерна - $60 \%$ НВ. Нормы поливов посевов зерновых озимых культур во время проведения опытного эксперимента составляли 300 $350 \mathrm{~m}^{3} /$ га в фазы кущения и налива, 400$450 \mathrm{~m}^{3} /$ га в фазу трубкования и $500 \mathrm{~m}^{3} /$ га в фазу колошения.

Кукуруза, выращиваемая на силос, наибольшим водопотреблением отличается во второй половине вегетации (в период от 15 листьев до выметывания метелки), в этот период предполивную влажность почвы нужно поддерживать на уровне $80 \%$ НВ, в остальные фазы развития она должна составлять 70-75\% НВ. Нормы полива этой культуры варьировали от 300-400 м³ $/$ га в первой половине вегетации до 500-600 м³ /га во второй половине ее роста и развития.

Люцерна, выращиваемая на зеленую массу и сено, наибольшим водопотреблением характеризуется в фазу бутонизации-цветения. В этот период влажность почвы необходимо поддерживать на уровне не ниже 75-80\% НВ, в остальные периоды - 70-75\% НВ. Режим орошения люцерны на семена предполагает поддержание влажности почвы на уровне 70-75\% НВ в период до начала цветения 
Таблица 1 - Количество и нормы поливов сельскохозяйственных культур в годы различной влагообеспеченности в степной и сухостепной зонах Поволжья

(данные ВолжНИИГиМ)

\begin{tabular}{|c|c|c|c|c|c|c|c|c|}
\hline \multirow{3}{*}{ Культура } & \multicolumn{6}{|c|}{ Число поливов } & \multirow{3}{*}{$\begin{array}{c}\text { Поливная } \\
\text { норма, } \\
\text { м³ }^{3} \text { га } \\
\text { (нетто) }\end{array}$} & \multirow{3}{*}{$\begin{array}{c}\text { Крити- } \\
\text { ческий } \\
\text { период по } \\
\text { отношению } \\
\text { к влаго- } \\
\text { обеспечен- } \\
\text { ности }\end{array}$} \\
\hline & \multicolumn{3}{|c|}{$\begin{array}{c}\text { Северное и Центральное } \\
\text { Заволжье (черноземы } \\
\text { и темно-каштановые почвы) }\end{array}$} & \multicolumn{3}{|c|}{$\begin{array}{c}\text { Южное Заволжье (каштановые } \\
\text { и светло-каштановые почвы) }\end{array}$} & & \\
\hline & $\begin{array}{c}\text { остро } \\
\text { засушливые } \\
\text { годы }\end{array}$ & $\begin{array}{c}\text { засушливые } \\
\text { годы }\end{array}$ & $\begin{array}{c}\text { умеренно } \\
\text { засушливые } \\
\text { годы }\end{array}$ & $\begin{array}{c}\text { остро } \\
\text { засушливые } \\
\text { годы }\end{array}$ & $\begin{array}{l}\text { засушли- } \\
\text { вые годы }\end{array}$ & $\begin{array}{c}\text { умеренно } \\
\text { засушливые } \\
\text { годы }\end{array}$ & & \\
\hline $\begin{array}{l}\text { Озимая } \\
\text { пшеница }\end{array}$ & $3-4$ & $2-3$ & $1-2$ & $4-5$ & $3-4$ & $2-3$ & $350-450$ & $\begin{array}{l}\text { трубкова- } \\
\text { ние- } \\
\text { колошение }\end{array}$ \\
\hline $\begin{array}{l}\text { Кукуруза } \\
\text { на силос и } \\
\text { зерно }\end{array}$ & $4-6$ & $3-5$ & $2-3$ & $5-7$ & $4-6$ & $3-4$ & $350-500$ & $\begin{array}{l}\text { цветение- } \\
\text { молочная } \\
\text { спелость }\end{array}$ \\
\hline $\begin{array}{l}\text { Люцерна } \\
\text { на сено }\end{array}$ & $6-7$ & $5-6$ & $4-5$ & $7-8$ & $6-7$ & $5-6$ & $400-500$ & $\begin{array}{c}\text { конец буто- } \\
\text { низации- } \\
\text { цветение }\end{array}$ \\
\hline $\begin{array}{l}\text { Суданская } \\
\text { трава }\end{array}$ & $4-6$ & $3-5$ & $2-3$ & $5-7$ & $4-6$ & $3-4$ & $300-450$ & $\begin{array}{c}\text { выметыва- } \\
\text { ние } \\
\text { метелки }\end{array}$ \\
\hline $\begin{array}{l}\text { Соя на } \\
\text { зерно }\end{array}$ & $4-5$ & $3-4$ & $1-3$ & $5-6$ & $4-5$ & $2-4$ & $350-450$ & $\begin{array}{c}\text { цветение- } \\
\text { формирова- } \\
\text { ние зерна }\end{array}$ \\
\hline
\end{tabular}

и снижение ее в последующие фазы развития культуры до 60-65\% НВ. Поливные нормы посевов люцерны и ее смесей составляли на начало отрастания 300$350 \mathrm{~m}^{3} /$ га, в период максимального водопотребления - 400-500 м³ $/$ га.

Для многолетних кормосмесей и культурных пастбищ влажность почвы в период бутонизации бобовых и колошения злаковых трав должна быть не ниже $80 \%$ НВ, в последующие фазы - 70-75\% НВ.

Для сои, выращиваемой на зерно, режим орошения должен быть следующий: 70\% НВ в начальные периоды развития культуры, $80 \%$ НВ - в период от бутонизации до налива зерна и $70 \%$ HB - в последующие фазы вегетации. Рациональная норма полива сои в условиях проведения исследований колебалась от 300 до 550 м $^{3} /$ га.

Следует прекращать поливы: зерновых культур - в фазу восковой-начало полной спелости; кукурузы - при наступлении молочной спелости, за 4-5 дней до начала уборки; люцерны, выращиваемой на зеленую массу, и травосмесей - за 4-5 дней до укоса, люцерны на семена при побурении 70-75\% бобов.

На участках с близким уровнем грунтовых вод (1,0-1,5 м) поливы не проводят. Для поливов участков с уровнем грун- товых вод менее 3 м должна быть проведена корректировка поливных норм в сторону их уменьшения на 30-40\%.

Разработанные режимы орошения сельскохозяйственных культур для степной и сухостепной зон Поволжья приведены в таблице 1.

Заключение. Система поливов должна обеспечивать строгое распределение норм водоподачи в период вегетации сельхозкультур с учетом мелиоративного состояния территории, испаряющей способности приземного слоя (засушливости периода), оптимизации объема поданной на поле воды в период наибольшей потребности растений, недопущения длительного переувлажнения верхних слоев почвы и потерь влаги за пределами корнеобитаемого слоя, использования растениями исходных почвенных влагозапасов в объеме не менее $15-25 \%$ от величины суммарного испарения. Такой строго регламентированный водосберегающий расход влаги сельскохозяйственными культурами позволяет уменьшить оросительные нормы (без существенного снижения урожайности) и предотвратить инфильтрационные потери в грунтовые воды, сохранив близкие к природным условия агроландшафта.

Мероприятия, направленные на повышение эффективности водопользования в орошаемом земледелии должны в первую очередь контролировать внедрение норм водоподачи и режимов орошения и предусматривать мониторинг и оперативную корректировку режимов орошения с учетом метеорологии и конкретных почвенномелиоративных условий агроландшафта.

\section{Библиографический список}

1. Алпатьев, А.М. О методах расчета потребности в воде культурных фитоценозов в связи с развитием орошения в СССР / А.М. Алпатьев // Биологические особенности орошаемого земледелия. - М., АН СССР, 1974. - С. 85-92.

2. Безднина, С.Я. Водно-экологические аспекты мелиоративной деятельности [Текст] / С.Я. Безднина // Вопросы мелиорации. - 2004. - №1. - С. 32-35.

3. Ерхов, Н.С. Сельскохозяйственная мелиорация и водоснабжение [Текст] / Н.С. Ерхов, А.С. Мисенев, Н.И. Ильин. - М.: Колос, 1983. - $351 \mathrm{c}$.

4. Костяков, А.Н. Основы мелиораций [Текст] / А.Н. Костяков. - М.: Сельхозгиз, 1960. - 621 с.

\section{Bibliographic list}

1. Alpatov, A.M. Methods of calculation of water requirements of cultural phytocenoses in connection with irrigation development in the USSR [Text] / A.M. Alpatov // Biological features of irrigated agriculture. - M., USSR Academy of Sciences, 1974. - P. 85-92.

2. Besedina, S.J. Aqueous-environmental aspects of reclamation activities [Text] / S.J. Besedina // Reclamation. - 2004. - №1. - P. 32-35.

3. Erchov, N.S. Agricultural irrigation and water supply [Text] / N.S. Erchov, A.S. Misenes, N.And. Ilyin. - Moscow: Kolos, 1983. - 351 p.

4. Kostyakov, A.N. Fundamentals of reclamation [Text] / A.N. Kostyakov. - M.: Selkhozgiz, 1960. - 621 p. 
5. Кружилин, И.П. Водосбережение в орошаемом земледелии / И.П. Кружилин, А.А. Новиков, А.Г. Болотин // Роль мелиорации земель в реализации государственной научно-технической политики в интересах развития сельского хозяйства: материалы Международной научно-практической конференции, посвященной 50-летию Всероссийского научно-исследовательского института орошаемого земледелия, Волгоград, 06-09 сентября 2017 г. - Волгоград: ВНИИОЗ, 2017. - С. 43-48.

6. Маслова, В.В. Современное состояние аграрного сектора России [Текст] / В.В. Маслова // Бюджет. RU. Сельское хозяйство. - 2011. - №5. - [Электронный pecypc http://bujet.ru/ article/133387.php.].

7. Мелихова, Н.П. Оптимизация водного режима культур орошаемых севооборотов - важный фактор повышения их продуктивности и плодородия почв / Н.П. Мелихова [и др.] // Орошаемое земледелие. - 2018. - №4. - С. 56-59.

8. Морковин, В.Т. Расчет экологически безопасных норм водопотребления и режимов орошения сельскохозяйственных культур / В.Т. Морковин, В.В. Иванов, В.В. Корсак // Техническое совершенствование и эксплуатации оросительных систем в засушливой зоне Российской Федерации: Сб. науч. тр. - М.: ЦНТИ Мелиоводинформ, 2000. - С. 140-147.

9. Нагорный, В.А. Основы водосбережения при орошении в Саратовской области. - Саратов: СГАУ им. Н.И. Вавилова, 2001. - 153 с.

10. Новикова, И.В. Оросительные нормы сельскохозяйственных культур при хозяйственно-экономических и экологических ограничениях / И.В. Новикова, Г.А. Сенчуков, Е.Н. Лунева // Орошаемое земледелие. - 2015. - №3. - С. 17-18.

11. Парфенова, Н.И. Экологические принципы регулирования гидрогеохимического режима орошаемых земель [Текст] Н.И. Парфенова, Н.М. Решеткина // Санкт-Петербург: Гидрометеоиздат, 1995. - 15 с.

12. Рекомендации по рациональным экологически обоснованным оросительным нормам на планируемую урожайность силосной кукурузы, люцерны, озимой пшеницы, сои, гречихи и кормовых смесей для Саратовской области [Текст] / Сост. Н.А. Пронько, В.К. Брель, В.А. Шадских, В.В. Корсак, С.В. Затинацкий, Ю.И. Панченко // Саратов: ФГОУ ВПО СГАУ им. Н.И. Вавилова, 2011. - 26 с.

13. Романова, Л.Г. Расчет экологически обоснованных норм орошения по агроландшафтным зонам Поволжья с помощью имитационного моделирования / Л.Г. Романова, Н.А. Тимофеева // Материалы Междунар. науч.-практ. конф. ФГБНУ ВНИИМЗ «Инновационные агро- и биотехнологии в адаптивно-ландшафтном земледелии на мелиорированных землях», Тверь, 1516 сентября. - 2016. - С. 252-258.

14. Шадских, В.А. Основные принципы оптимизации экологической ситуации орошаемых агроландшафтов степной и сухостепной зон Поволжья / В.А. Шадских, Л.Г. Романова, В.Е. Кижаева // Мелиорация и водное хозяйство. - 2017. - №6. - С. 17-20.

15. Шадских, В.А. Режим влажности почвы в севообороте сухостепной зоны Поволжья / В.А. Шадских, В.Е. Кижаева // Мелиорация и водное хозяйство. - 2018. - №5. - С. 21-24.

16. Шадских, В.А. Ресурсосберегающий поливной режим в системе орошаемых севооборотов / В.А. Шадских, В.Е. Кижаева, О.Л. Рассказова // Роль мелиорации земель в реализации государственной научно-технической политики в интересах устойчивого развития сельского хозяйства: Материалы Междунар. науч.-практ. конф., к 50-летию ВНИИОЗ. - Волгоград, 2017. - С. 218-223.

Дополнительные сведения об авторах:

Владимир Александрович Шадских, главный научный сотрудник отдела комплексной мелиорации и экологии, volzniigim@bk.ru,

Вера Евгеньевна Кижаева, ведущий научный сотрудник отдела комплексной мелиорации и экологии, volzniigim@bk.ru,

Любовь Геннадьевна Романова, старший научный сотрудник отдела комплексной мелиорации и экологии, volzniigim@bk.ru,

Ольга Леонидовна Рассказова, старший научный сотрудник отдела комплексной мелиорации и экологии, volzniigim@bk.ru
5. Kruzhilin, I.P. Water conservation in irrigated agriculture / I.P. Kruzhilin, A.A. Novikov, A.G. Bolotin // The role of land reclamation in the implementation of the state scientific and technical policy in the interests of agricultural development: proceedings of the International Scientific and Practical Conference dedicated to the 50th anniversary of the All-Russian Scientific Research Institute of Irrigated Agriculture, Volgograd, September 06-09, 2017. Volgograd: VNIIOZ, 2017. - P. 43-48.

6. Maslova, V.V. The current state of the agricultural sector of Russia [Text] / V.V. Maslova // Budget. RU. Agriculture. - 2011. - №5. - [Electronic resource http://bujet.ru/article/133387.php.].

7. Melikhova, N.P. Optimization of the water regime of irrigated crop rotation crops is an important factor in increasing their productivity and soil fertility / N.P. Melikhova [et al.] // Irrigated agriculture. 2018. - №4. - P. 56-59.

8. Morkovin, V.T. Calculation of environmentally friendly norms of water consumption and crop irrigation regimes / V.T. Morkovin V.V. Ivanov, V.V. Korsak // Technical improvement and operation of irrigation systems in the arid zone of the Russian Federation: Sat. scientific tr. - M.: TSNTI Meliovodinform, 2000. - P. 140-147.

9. Nagorny, V.A. Basics of water conservation in irrigation in the Saratov region. - Saratov: SSAU im. N.I. Vavilova, 2001. - 153 p.

10. Novikova, I.V. Irrigation norms of agricultural crops under economic, economic and environmental restrictions / I.V. Novikova, G.A. Senchukov, E.N. Luneva // Irrigated agriculture. - 2015. - №3. - P. 17-18.

11. Parfenova, N.I. Ecological principles of regulation of the hydrogeochemical regime of irrigated lands [Text] / N.I. Parfenova, N.M. Reshetkina // St. Petersburg: Gidrometeoizdat, 1995. - 15 p.

12. Recommendations on rational environmentally sound irrigation norms for the planned yield of silage corn, alfalfa, winter wheat, soy, buckwheat and feed mixtures for the Saratov region [Text] / Comp. O.N. Pronko, V.K. Brel, V.A. Shadskikh, V.V. Korsak, S.V. Zatinatsky, Yu.I. Panchenko // Saratov: FSEI HPE SGAU named after N.I. Vavilova, 2011. - 26 p.

13. Romanova, L.G. Calculation of environmentally sound irrigation norms for agrolandscape zones of the Volga region using simulation modeling / L.G. Romanova, N.A. Timofeeva // Materials of the Intern. scientific-practical conf. FSBI VNIIMZ «Innovative agro- and biotechnologies in adaptive landscape farming on reclaimed lands», Tver, September 15-16. - 2016. - P. 252-258.

14. Shadskikh, V.A. The basic principles of optimizing the ecological situation of irrigated agrolandscapes of the steppe and dry-steppe zones of the Volga region / V.A. Shadskikh, L.G. Romanova, V.E. Kizhaeva // Reclamation and water management. - 2017. - №6. - P. 17-20.

15. Shadskikh, V.A. Moisture regime of the soil in the rotation of the dry steppe zone of the Volga region / V.A. Shadskikh, V.E. Kizhaeva // Reclamation and water management. - 2018. - №5. - P. 21-24.

16. Shadskikh, V.A. Resource-saving irrigation regime in the system of irrigated crop rotation / V.A. Shadskikh, V.E. Kizhaeva, O.L. Rasskazova // The role of land reclamation in the implementation of the state scientific and technical policy in the interests of sustainable agricultural development: Materials of the Intern. scientific-practical Conf., to the 50th anniversary of VNIIOZ. - Volgograd, 2011.- P. 218223.

\section{Additional information about the authors:}

Vladimir Alexandrovich Shadskikh, chief researcher of the department of complex land reclamation and ecology, volzniigim@bk.ru,

Vera Evgenyevna Kizhaeva, leading researcher of the department of complex land reclamation and ecology, volzniigim@bk.ru,

Lyubov Gennadyevna Romanova, senior researcher of the department of complex land reclamation and ecology, volzniigim@bk.ru,

Olga Leonidovna Rasskazova, senior researcher of the department of complex land reclamation and ecology, volzniigim@bk.ru 